\title{
Multi-level examination of correlates of active transportation to school among youth living within 1 mile of their school
}

\author{
Kathleen M Gropp ${ }^{1}$, William Pickett ${ }^{1,2}$ and lan Janssen ${ }^{1,3^{*}}$
}

\begin{abstract}
Background: Active transportation to school is a method by which youth can build physical activity into their daily routines. We examined correlates of active transportation to school at both individual- (characteristics of the individual and family) and area- (school and neighborhood) levels amongst youth living within 1 mile (1.6 km) of their school.

Methods: Using the 2009/10 Canadian Health Behaviour in School-Aged Children (HBSC) survey, we selected records of students ( $n=3$ 997) from 161 schools that resided in an urban setting and lived within 1 mile from their school. Student records were compiled from: (1) individual-level HBSC student questionnaires; (2) area-level administrator (school) questionnaires; and (3) area-level geographic information system data sources. The outcome, active transportation to school, was determined via a questionnaire item describing the method of transportation that individual students normally use to get to school. Analyses focused on factors at multiple levels that potentially contribute to student decisions to engage in active transportation. Multi-level logistic regression analyses were employed.
\end{abstract}

Results: Approximately 18\% of the variance in active transportation was accounted for at the area-level. Several individual and family characteristics were associated with engagement in active transportation to school including female gender (RR vs. males $=0.86,95 \% \mathrm{Cl}$ : 0.80-0.91), having $\geq 2$ cars in the household (RR vs. no cars $=0.87$, 0.74-0.97), and family socioeconomic status (RR for 'not well off' vs. 'very well off' $=1.14,1.01-1.26$ ). Neighborhood characteristics most strongly related to active transportation were: the length of roads in the $1 \mathrm{~km}$ buffer (RR in quartile 4 vs. quartile $1=1.23,1.00-1.42$ ), the amount of litter in the neighborhood (RR for 'major problem' vs. 'no problem' $=1.47,1.16-1.57$ ), and relatively hot climates (RR in quartile 4 vs. quartile $1=1.33 \mathrm{Cl}, 1.05-1.53$ ).

Conclusion: Engagement in active transportation to school was related to multiple factors at multiple levels. We identified gender, perception of residential neighborhood safety, the percentage of streets with sidewalks, and the total length of roads as the most important correlates of active transportation to school.

Keywords: Active transportation, Adolescent, School, Neighborhood

\footnotetext{
* Correspondence: ian.janssen@queensu.ca

'Department of Community Health and Epidemiology, Queen's University, Kingston, ON, Canada

${ }^{3}$ School of Kinesiology and Health Studies, Queen's University, Kingston, ON K7L 3N6, Canada

Full list of author information is available at the end of the article
} 


\section{Introduction}

Active transportation is the engagement in physical activity specifically for travel and includes methods such as walking and bicycling [1]. Active transportation is one means by which children and youth can incorporate physical activity into their daily routines. Indeed, children and youth who walk or bicycle to school have higher overall physical activity [2] and cardiorespiratory fitness levels [3] and a healthier body composition [3]. Unfortunately, the proportion of children and youth who engage in active transportation to school has decreased by $8-10 \%$ in Canada over the last two decades [4] and by $25 \%$ in the United States over the last four decades [5], which is of obvious concern to public health. Evidence about the various factors that lead to decisions to engage in active transportation to school is fundamental to the development of effective health promotion strategies.

Correlates of active transportation to school exist at multiple levels, including characteristics of individual students and their families (individual-level) and characteristics of the students' schools and their neighborhoods (area-level). Individual and family characteristics that may be relevant include living in close proximity to school [6-9], male gender [6,9-11], ethnicities other than Caucasian $[6,12,13]$, low family socio-economic status $[14,15]$, and a non-traditional family structure $[14,15]$. While there is little information about the influence of schools and school policies on active transportation to school, one school-based active transportation study found that students attending private school were $40 \%$ less likely to engage in regular active transportation [16]. At the neighborhood-level, students who live in densely populated areas are more likely to engage in active transportation to school [12]. Another relevant neighborhood factor is the presence of sidewalks, which has consistently been shown to be a strong correlate [11,16-19]. Associations between active transportation and the design of road networks are less clear. A recent systematic review reported varying associations for intersection density, block length, and route directness [20]. Despite the interest in characteristics of the neighborhood, certain variables have not been examined, including neighborhood aesthetics (e.g., litter, condition of houses and buildings) and safety features (e.g., speed limits of roads surrounding the school).

Although the correlates of active transportation to school occur at multiple levels, the vast majority of existing studies on this topic have not simultaneously considered multiple factors at the various levels [7-9,11,13,18,21-25]. The few multi-level studies that exist have been conducted within small geographic areas $[8,9,11,17,22,26]$, which limits their generalizability. Multi-level research that examines a multitude of potential correlates could help illustrate the complexity behind decisions that govern whether or not youth travel to school in an active or passive manner. Furthermore, such research would help identify the strongest correlates, which in the shortterm may be identified for more focused study, and in the long-term may be addressed via preventive interventions.

We conducted a national analysis of possible individuallevel and area-level correlates of active transportation to school among urban Canadian youth aged 11-15 years who lived within 1 mile $(1.6 \mathrm{~km})$ of their school. Our goal was to identify major factors at multiple levels that govern decisions to engage in active transportation amongst youth not eligible for bussing and who live within a reasonable walking or biking distance from school. This study was exploratory and no a priori hypotheses were assumed, although our choices of variables for study were governed by existing literature.

\section{Methods}

\section{Overview of study design and measures}

The basis for this study was the 2009/10 Canadian Health Behaviour in School-Aged Children (HBSC) Survey. HBSC is a general health survey of grades 6-10 students conducted in affiliation with the World Health Organization. The 2009/10 Canadian HBSC, or the $6^{\text {th }}$ Canadian cycle, consisted of three main components: (1) a questionnaire completed by students that asked about their health behaviors (such as active transportation), lifestyle factors, and demographics, (2) an administrator questionnaire distributed to each school principal that inquired about school demographics, policy, infrastructure, and about the school neighborhood setting, and (3) geographic information systems (GIS) measures of built and social features in the school neighborhoods that were later linked with the HBSC data.

\section{Participants}

In Canada, the HBSC survey follows a systematic multistage cluster sample where individual students are nested in school classes, which in turn are nested within schools, followed by school boards. This sampling approach adheres to the standard international protocol [27]. In 2009/10 the HBSC survey was administered to 26078 Canadian students in grades 6-10 from 436 schools in 11 territories and provinces (all jurisdictions with the exception of Prince Edward Island and New Brunswick participated). With respect to human subjects, consent to participate was obtained from school boards, individual schools, parents or guardians (either explicitly or implicitly determined by school board policy), and from individual students. Ethics approval for the Canadian HBSC was granted by the General Research Ethics Board of Queen's University.

For this study, we only included participating students who attended school in an urban core, as indicated by the school postal codes. An urban core is defined as a 
large urban area that has a population of at least 50000 in the urban core in the case of a Census Metropolitan Area, or a population of at least 10000 in the urban core for a Census Agglomeration". In Canada, postal codes provide specific indicators of location of residence in urban core settings, but not in rural locations [28].

To be included in this study we required that the participants lived within a reasonable walking distance of their school, estimated at 1 mile $(1.6 \mathrm{~km})$ or less. Walking distances were conservatively estimated using direct distance from the geographical center of their postal code to the school address. The inclusion criteria limited the study base to students who had a realistic opportunity to regularly engage in active transportation to school. By school board policy, Canadian students who live more than 1 mile from school are typically offered transportation by school bus, although this distance can vary. A large percentage (43\%) of urban students did not report their postal code in the HBSC survey, and to increase the study sample size, for these students we used their answers to questions about "travel time to school" and "usual mode of transportation to school" to estimate whether they lived within the 1 mile distance. Students who reported that their travel time to school was 15 minutes or less by walking, or less than 5 minutes for every other mode of transportation (bicycle, car, bus, etc.), were therefore also included. The final sample size of urban youth available for analysis was 3,997 (see Figure 1 for a participant flow diagram).

\section{Outcome - active transportation to school}

The outcome of interest was regular engagement in active transportation to school, either via walking or bicycling. Participants answered the following HBSC survey question: "On a typical day, the MAIN part of your journey TO school is made by..." with the following options: 1 ) walking; 2) bicycle; 3 ) bus, train, streetcar, subway, or boat/ ferry; 4) car, motorcycle, or moped; 5) other. Responses were grouped dichotomously: those who answered "walking" or "bicycle" were categorized as students who regularly engage in active transportation to school, while those who answered 'bus, train, streetcar, subway, boat/ ferry, car, motorcycle, moped' were categorized as individuals who do not. Participants who answered 'other' to this question were excluded to minimize possible misclassification. Intra-rater reliability analyses for the HBSC active transportation question suggest there is an excellent level of agreement (Cronbach's alpha $\geq 0.80$ ) between multiple student reports, including reports examined across seasons [29].

\section{Possible correlates of active transportation}

We constructed a list of possible correlates of active transportation to school based on the evidence in

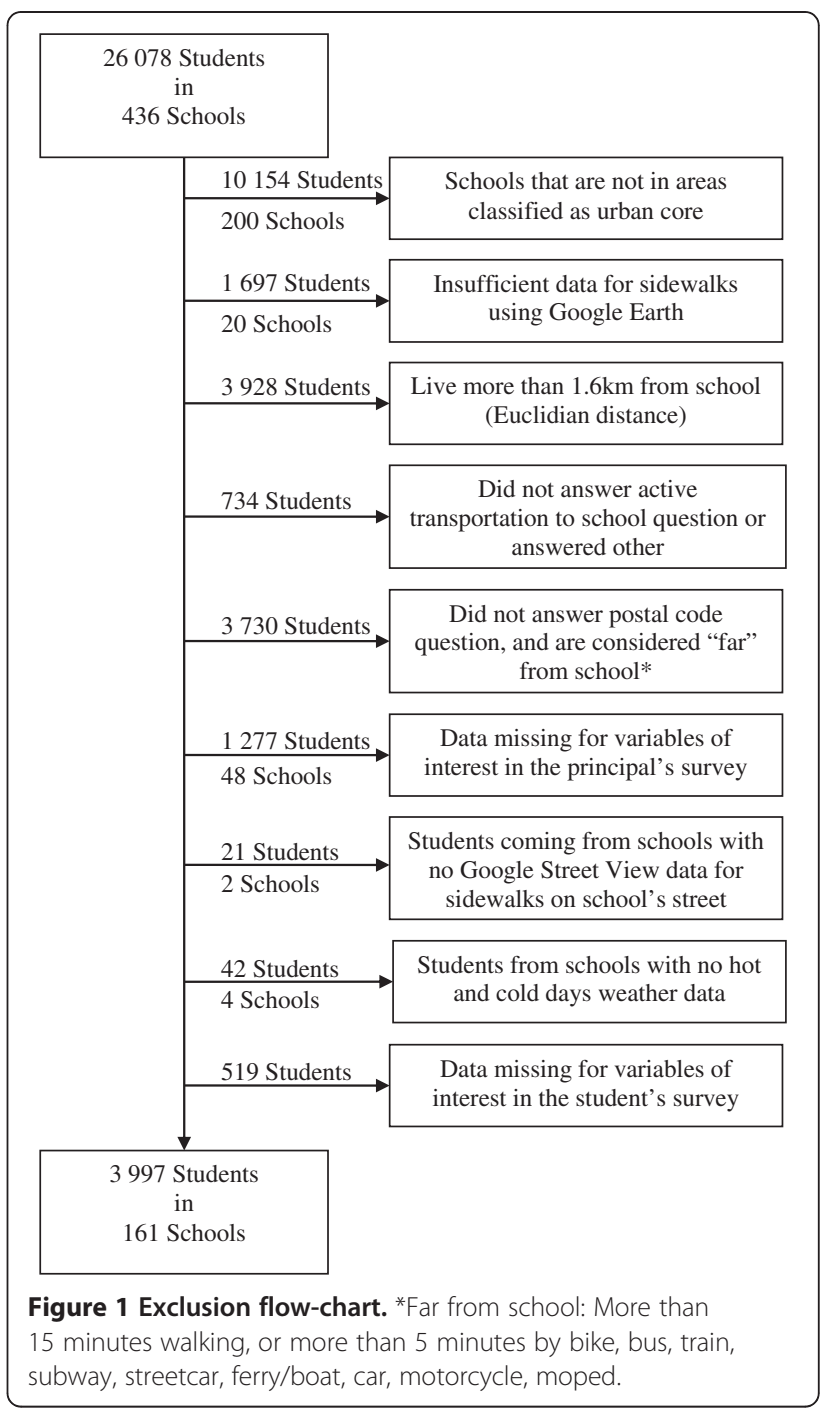

existing literature. We then cross-referenced this list against the HBSC and GIS data available to our research team and examined all of the possible correlates that we could.

\section{Individual and family correlates (individual-level data)}

Eight items describing potential correlates of the individual participants and their families were obtained via the HBSC student questionnaire: gender (male or female), grade (6-8 and 9-10), ethnicity (four composite categories consisting of: Caucasian only, Caucasian and other, Aboriginal, and other), number of siblings (0, 1, 2 or more), family structure (living with both parents, living with one parent and a step-parent, living with a single parent, and all other living situations), family socio-economic status (SES) as measured by perceived relative affluence ( 5 categories from "very well off" to "not well off at all"), the number of cars in the household ( $0,1,2$ or more), and perceived residential neighborhood safety (where you live, is it safe for 
children to play outside? (5 categories: "strongly agree" to "strongly disagree").

\section{School correlates (area-level data)}

Three items of the school were measured using the HBSC administrator questionnaire. These items focused on school active transportation policies, programs, and infrastructure. A series of questions inquired about whether the school promoted active transportation by: (1) having walk and/or bike to school days or walking school buses; (2) identifying safe routes to walk or bicycle to school; and (3) providing bicycle racks in safe locations. All three of these items were dichotomized as "yes" or "no" for analytical purposes. Schools with administrators who answered "don't know" to these questions were classified as "no".

\section{Neighborhood correlates (area-level data)}

Aesthetics Two items that reflect neighborhood aesthetics were measured using the HBSC administrator questionnaire: (1) presence of litter in the school neighborhood; and (2) vacant or shabby housing in the school neighborhood. Four possible response categories were available, ranging from "no problem" to "major problem".

Twelve items of the neighborhood were measured with GIS using the CanMap Route Logistics database (DMTI Spatial Inc., Markham, ON) in ArcView version 9.3 software, PCensus for MapPoint software (Tetrad Computer Applications Inc., Vancouver, BC), Google Earth and Google Street View software (Google Inc., Mountain View, CA), and Environment Canada data (National Climate Data and Information Archive). Some of these variables were obtained from a $1-\mathrm{km}$ radius circular buffer surrounding the school, some were obtained at the exact school address, and others were obtained for the municipality where the school was located.

Sidewalk measures The first of the GIS measures consisted of whether there was at least one sidewalk leading directly to the school. This was measured using Google Street View. If the Google Street View image confirmed that there was a sidewalk on either side of the street on which the school was located, this variable was categorized as "yes", otherwise it was categorized as a "no". The use of Google Street View as an alternative to physical audit has been validated, and measures (such as the presence of recreational buildings and parks) have produced observed agreement correlations of 0.92 and 0.95 , respectively [30].

The percentage of roads with sidewalks in the $1 \mathrm{~km}$ (0.62 miles) buffer surrounding each school was obtained from Google Earth and ArcGIS, as previously described in detail [31]. The length of roads with a sidewalk (on either side) was gathered and divided by the total length of roads. This variable was then categorized into quartiles.
This was done by first calculating the distance of roads in the buffer using the CanMap Route Logistics database in ArcGIS. The road network was exported from ArcGIS into Google Earth, and within Google Earth the road segments were superimposed onto the street view images. Road segments that did not have a sidewalk were deleted from the road network within Google Earth. After deletions, the revised road network was imported back into ArcGIS so that the sidewalk distances could be calculated.

Road measures Four neighborhood road measures (total length of roads, percentage of roads with speed limits less than or equal to $60 \mathrm{~km} / \mathrm{h}$, speed limit of the school's road, and street connectivity) were obtained from CanMap Route Logistics in ArcGIS software. The CanMap Route Logistics database provides geospatial information on roads and their segments (e.g., blocks) across the country. This includes information on the length of each road segment and its speed limit. Total length of roads was calculated in ArcGIS as the distance of all road segments within the $1 \mathrm{~km}$ buffer. The percentage of roads with speed limits $\leq 60 \mathrm{~km} / \mathrm{h}$ (37 miles/h) was calculated by dividing the length or all road segments within the buffer with speed limits $\leq 60 \mathrm{~km} / \mathrm{h}$ by the total length or roads within the buffer. The speed limit of each school's road was categorized as $\leq 40 \mathrm{~km} / \mathrm{h}$ (25 miles/h), $50 \mathrm{~km} / \mathrm{h}$ (31 miles/h), or $\geq 60 \mathrm{~km} / \mathrm{h}$ based on the speed limit of the road segment at the school's main entrance. The remaining three variables were obtained for the $1 \mathrm{~km}$ radial buffer surrounding the school. Street connectivity was calculated as a composite measure of intersection density, average block length, and connected node ratio, similar to measures identified by others [32-34]. Intersection density was calculated as the number of intersections divided by the total land area in each buffer. Average block length was calculated as the total length of roads divided by the number of intersections. The connected node ratio was calculated by dividing the number of true intersections by the number of all intersections including cul-de-sacs and dead ends. Based upon prior work [34], a principal component factor analysis showed that each street connectivity variable was related; factor loadings were: $0.93,0.66,0.89$ for intersection density, average block length, and connected node ratio variables respectively (Cronbach's alpha standardized $=0.78$ ). These variables were combined with equal weight, than ranked as a composite variable.

SES Neighborhood SES was measured in the $1 \mathrm{~km}$ buffer surrounding each school, based upon the 2006 Canadian Census, using PCensus for MapPoint software. The overall median household income was calculated by weighting 
each census block by the total population. This variable was categorized into quartiles.

Climate Annual climate variables (calculated from at least 15 years of data between 1971 and 2000) were obtained for each school using the Environment Canada National Climate Data as inferred from the most proximal weather station to each school. These measures included: average temperature $\left({ }^{\circ} \mathrm{C}\right)$, average annual rainfall $(\mathrm{mm})$, average annual snowfall $(\mathrm{cm})$, average annual number of extreme hot days (maximum temperature $>30^{\circ} \mathrm{C}$ or $>80^{\circ} \mathrm{F}$ ), and average number of extreme cold days (minimum temperature $<-20^{\circ} \mathrm{C}$ or $<-4^{\circ} \mathrm{F}$ ). Each climate variable was categorized into quartiles.

\section{Statistical analysis}

Statistical analyses were performed with SAS version 9.2 (SAS Inc., Carry, NC). Potential correlates of active transportation were initially described for the sample using conventional descriptive statistics. They were further described by the percentage of individuals in each category that engaged in active transportation to school.

Prior to performing multi-level analyses, an empty model was run to calculate the intra-class correlation (ICC), which reflects the proportion of the total variance in the active transportation outcome explained by the area-level. An ICC value of $18 \%$ was obtained, suggesting that a large amount of variation was accounted for by school and neighborhood characteristics [35]. This justified the use of multi-level analytical techniques in subsequent analyses.

Our approach to statistical modeling was governed by the following strategy. Due to the exploratory nature of our investigation, a backwards selection approach was employed. Studies of the built environment and walking and bicycling have found more variation at the individualvs. area-levels [36,37]. Therefore, we performed multilevel modeling in steps, beginning with building a model at the individual-level (individual and family), followed by the introduction of variables at the area-level (school and neighborhood). Our goal was to create a parsimonious list of potential correlates of active transportation to school while controlling for all of the selected variables at multiple levels.

Our multi-level models were then built using the following hierarchal approach: 1) all individual-level variables were considered in bivariate models with active transportation to school as the outcome (multivariate model 1); 2) backwards selection methods were performed next, with a cut-off value of $\mathrm{p}<0.05$ for retention of individual-level variables; 3$)$ area-level variables were then added to the significant individual-level variables from multivariate model 1 to create multivariate model 2; 4) backwards selection was performed for the area-level
Table 1 Individual-level (individual and family) characteristics of urban youth $(n=3$ 997) sampled for study of active transportation in Canada

\begin{tabular}{lc}
\hline Characteristic & N (\%) \\
\hline Gender & \\
Male & $1930(48.3)$ \\
Female & $2067(51.7)$ \\
Grade & \\
6 & $918(22.8)$ \\
7 & $915(22.9)$ \\
8 & $932(23.3)$ \\
9 & $599(15.0)$ \\
10 & $639(16.0)$ \\
Ethnicity & \\
Caucasian only & $2443(61.1)$ \\
Caucasian and other & $201(5.0)$ \\
Aboriginal & $396(9.9)$ \\
Other & $957(23.9)$
\end{tabular}

Number of siblings

0

608 (15.2)

1

$2+$

$1729(43.3)$

1660 (41.5)

Adults at home

Both mother and father

$2655(66.4)$

One parent and one step-parent

$418(10.5)$

Single parent

$775(19.4)$

Other

$149(3.7)$

Family SES

Very well off

904 (22.6)

Well off

1317 (32.9)

Average

$1405(35.2)$

Not very well off

$266(6.7)$

Not at all well off

105 (2.6)

Number of cars in household

0

176 (4.4)

1

1186 (29.7)

$2+$

$2635(65.9)$

Residential neighborhood is safe for children

$\begin{array}{lc}\text { Strongly agree } & 1109(27.7) \\ \text { Agree } & 1792(44.8) \\ \text { Neither agree nor disagree } & 750(18.8) \\ \text { Disagree } & 242(6.1) \\ \text { Strongly disagree } & 104(2.6)\end{array}$


Table 2 Area-level characteristics of the schools and neighborhoods of urban Canadian youth ( $n=3$ 997)

\begin{tabular}{lll}
\hline $\mathrm{N}(\%)$ & Median (IQR) \\
\hline
\end{tabular}

\section{School Characteristics}

Bicycle storage available in a safe location

$\begin{array}{lc}\text { No } & 835(20.9) \\ \text { Yes } & 3162(79.1)\end{array}$

Has walk/bike to school days and/or walking school bus programs

No $2751(68.8)$

Yes

$1246(31.2)$

Identification of safe walking/biking routes to school

$\begin{array}{ll}\text { No } & 2347(58.7) \\ \text { Yes } & 1650(41.3)\end{array}$

Neighborhood Characteristics

Sidewalk leading to school

\begin{tabular}{|c|c|c|}
\hline No & $161(4.0)$ & \\
\hline Yes & $3836(96.0)$ & \\
\hline$\%$ of roads with sidewalks & & $64.6(47.4-83.0)$ \\
\hline \multicolumn{3}{|c|}{ Speed limit of school's road (km/h) } \\
\hline$\leq 40$ & $311(7.8)$ & \\
\hline 50 & $3390(84.8)$ & \\
\hline$\geq 60$ & $296(7.4)$ & \\
\hline
\end{tabular}

$\%$ of roads with speed limit $\leq 60 \mathrm{~km} / \mathrm{h}$

$\begin{array}{lc}<90 & 493(12.3) \\ 90-93.99 & 851(21.3) \\ 94-99.99 & 1196(29.9) \\ 100 & 1457(36.5)\end{array}$

Total length of roads $(\mathrm{km})$

Street connectivity

1 (lowest connectivity)

$1176(29.4)$

2

$1034(25.9)$

$951(23.8)$

4 (highest connectivity)

$836(20.9)$

Litter in neighborhood

No problem

$1285(32.1)$

Minor problem

$2216(55.4)$

Moderate problem

$399(10.0)$

Major problem

$97(2.4)$

Vacant or shabby housing

$\begin{array}{lc}\text { No problem } & 2999(75.0) \\ \text { Minor problem } & 750(18.8) \\ \text { Moderate problem } & 192(4.8) \\ \text { Major problem } & 56(1.4)\end{array}$

Neighborhood SES

(median family income, \$CAD)

Average temperature $\left({ }^{\circ} \mathrm{C}\right)$

Average annual rain $(\mathrm{mm})$
Table 2 Area-level characteristics of the schools and neighborhoods of urban Canadian youth ( $n=3$ 997) (Continued)

\begin{tabular}{lc}
\hline Average annual snow $(\mathrm{cm})$ & $231(195-304)$ \\
Average number of hot days & $4.5(0.5-11.4)$ \\
Average number of cold days & $26.0(0.6-47.7)$ \\
\hline
\end{tabular}

$I Q R=$ interquartile range.

variables in multilevel model 2 , this time with a cut-off value of $p<0.20$ as power was less for the area-level variables, to create the final model (multivariate model 3). If any variable or dummy variable had significance at $\mathrm{p}<0.05$ ( $p<0.20$ for the area level variables), or the test for linear trend across categories was significant $(p<0.05)$, they were retained in the backwards selection modeling approach. Because the analyses were exploratory, we selected a $\mathrm{p}<0.20$ for the area-level variables. This was done to ensure that we did not exclude area-level variables in the model building process that could achieve significance, but only after controlling for other covariates.

All models were fit as generalized linear models and were built with the SAS GLIMMMIX procedure with a binomial distribution and a logit link to account for the clustered nature of the data. We assumed random intercepts but fixed effects. A Newton-Raphson with ridging technique was applied to all multilevel logistic models to optimize convergence. Odds ratios were converted to relative risks (RR), as per existing precedents [38], $R R=O R$ / [ $(1-\mathrm{Po})+(\mathrm{OR} \times \mathrm{Po})]$, where Po is the prevalence of active transportation in the referent group for each variable.

Additionally, we calculated the population attributable risk (PAR) to estimate the proportion of active transportation to school attributed to the correlates at the different levels. PAR was calculated based upon the RR estimates generated in multivariate model 3 with the following equation: $(\mathrm{Pe}(\mathrm{RR}-1)) /(1+\mathrm{Pe}(\mathrm{RR}-1))$ where Pe is the proportion of individuals exposed in similar populations [39]. For variables with more than two categories, PAR was calculated for each of the non-referent categories and then summed to obtain an overall PAR estimate. For variables with an RR less than 1 , the effect was inverted to obtain an RR $>1$ prior to calculation of the PAR.

\section{Results}

Individual and family characteristics (individual-level) of the urban sample of students who lived in close proximity of their school are profiled in Table 1. A total of 3997 students were available for analysis, with approximately equal numbers of boys and girls. The majority of the students were in grades 6 to 8 , and there was considerable variation in social factors relevant to Canadian families and students' possible choices to engage in active 
Table 3 Bivariate and multivariate (Model 1) relationships of individual-level characteristics and active transportation to school ( $\mathrm{N}=3$ 997)

\begin{tabular}{|c|c|c|c|}
\hline \multirow[t]{2}{*}{ Individual-level characteristics } & \multirow{2}{*}{$\begin{array}{l}\% \text { Engaged in } \\
\text { active } \\
\text { transportation }\end{array}$} & \multirow{2}{*}{$\frac{\text { Bivariate model }}{\mathrm{RR}(95 \% \mathrm{Cl})}$} & \multirow{2}{*}{$\frac{\text { Multivariate model }}{\mathrm{RR}(95 \% \mathrm{Cl})}$} \\
\hline & & & \\
\hline \multicolumn{4}{|l|}{ Gender } \\
\hline Male & 67.6 & 1.00 & 1.00 \\
\hline Female & 57.9 & $0.86(0.81-0.91)$ & $0.85(0.80-0.90)$ \\
\hline \multicolumn{4}{|l|}{ Grade } \\
\hline 6 & 58.6 & 1.00 & 1.00 \\
\hline 7 & 62.3 & $1.06(0.97-1.15)$ & $1.08(0.99-1.17)$ \\
\hline 8 & 64.1 & $1.07(0.97-1.17)$ & $1.09(0.99-1.19)$ \\
\hline 9 & 61.9 & $1.12(0.99-1.23)$ & $1.11(0.99-1.23)$ \\
\hline 10 & 67.3 & $1.14(1.01-1.25)$ & $1.13(1.00-1.24)$ \\
\hline$P$ trend & & 0.03 & 0.05 \\
\hline \multicolumn{4}{|l|}{ Ethnicity } \\
\hline Caucasian only & 60.3 & 1.00 & 1.00 \\
\hline Caucasian and other & 70.2 & $1.09(0.95-1.21)$ & $1.11(0.97-1.23)$ \\
\hline Aboriginal & 69.2 & $1.08(0.98-1.18)$ & $1.03(0.92-1.14)$ \\
\hline Other & 64.1 & $0.92(0.84-1.00)$ & $0.92(0.84-1.00)$ \\
\hline \multicolumn{4}{|l|}{ Number of siblings } \\
\hline 0 & 65.5 & 1.00 & 1.00 \\
\hline 1 & 60.1 & $0.92(0.84-1.00)$ & $0.96(0.88-1.03)$ \\
\hline $2+$ & 64.2 & $0.97(0.90-1.05)$ & $1.01(0.93-1.08)$ \\
\hline$P$ trend & & 0.88 & 0.38 \\
\hline \multicolumn{4}{|l|}{ Adults at home } \\
\hline Both mother and father & 59.6 & 1.00 & 1.00 \\
\hline One parent and one step-parent & 67.5 & $1.11(1.02-1.20)$ & $1.08(0.98-1.17)$ \\
\hline Single parent & 69.0 & $1.13(1.06-1.19)$ & $1.06(0.98-1.14)$ \\
\hline Other & 69.1 & $1.13(0.97-1.26)$ & $1.08(0.92-1.23)$ \\
\hline \multicolumn{4}{|l|}{ Family SES } \\
\hline Very well off & 57.1 & 1.00 & 1.00 \\
\hline Well off & 62.3 & $1.09(1.00-1.21)$ & $1.07(0.99-1.15)$ \\
\hline Average & 66.1 & $1.17(1.10-1.25)$ & $1.15(1.07-1.23)$ \\
\hline Not very well off & 66.2 & $1.16(1.04-1.28)$ & $1.14(1.00-1.26)$ \\
\hline Not at all well off & 59.1 & $1.02(0.82-1.20)$ & $0.97(0.77-1.16)$ \\
\hline$P$ trend & & 0.0005 & 0.009 \\
\hline \multicolumn{4}{|l|}{ Number of cars in household } \\
\hline 0 & 76.7 & 1.00 & 1.00 \\
\hline 1 & 68.6 & $0.94(0.82-1.04)$ & $0.94(0.82-1.03)$ \\
\hline $2+$ & 59.0 & $0.85(0.72-0.95)$ & $0.85(0.73-0.97)$ \\
\hline$P$ trend & & $<.0001$ & 0.0001 \\
\hline \multicolumn{4}{|c|}{ Residential neighborhood is safe for children } \\
\hline Strongly agree & 63.5 & 1.00 & 1.00 \\
\hline Agree & 57.9 & $1.02(0.96-1.08)$ & $1.01(0.94-1.07)$ \\
\hline Neither agree nor disagree & 63.6 & $0.99(0.91-1.06)$ & $0.96(0.88-1.04)$ \\
\hline Disagree & 63.0 & $0.87(0.75-0.99)$ & $0.84(0.72-0.96)$ \\
\hline
\end{tabular}


Table 3 Bivariate and multivariate (Model 1) relationships of individual-level characteristics and active transportation to school ( $\mathbf{N}=3$ 997) (Continued)

\begin{tabular}{|c|c|c|c|}
\hline Strongly disagree & 62.2 & $0.98(0.81-1.14)$ & $0.96(0.77-1.12)$ \\
\hline $\mathrm{P}$ trend & & 0.14 & 0.036 \\
\hline
\end{tabular}

$R R(95 \% \mathrm{Cl})=$ relative risk (95\% confidence interval).

transportation to school. With respect to the study outcome, $62.6 \%$ engaged in regular active transportation to school. Table 2 further describes the distribution of the student sample by school and neighborhood characteristics (area-level) that could potentially impact active transportation choices.

Table 3 summarizes bivariate, then adjusted (multivariate model 1), associations between each individual-level variable and engagement in active transportation to school. While the bivariate analyses indicated that a number of individual-level factors are potential correlates of active transportation, multivariate model 1 (individually adjusted) results suggested a more modest list of correlates. Table 4 extends these results through the examination of area-level correlates of the school and neighborhood; few of these factors achieved statistical significance. The final multilevel model (multivariate model 3) is presented in Table 5.

The final multivariate model indicates that factors at both individual and area-levels were associated with active transportation. Individual and family characteristics (individual-level) included: gender (female: $\mathrm{RR}=0.86$, 95\% CI: 0.80-0.91); living with one parent and one stepparent $(\mathrm{RR}=1.10,95 \% \mathrm{CI}: 1.00-1.19)$; "well off" $(\mathrm{RR}=1.08$, 95\% CI: $1.00-1.16)$ to "not very well off" $(R R=1.14,95 \%$ CI: 1.01-1.26) perceived family affluence; two or more cars in the household ( $\mathrm{RR}=0.87,95 \% \mathrm{CI}$ : 0.74-0.97); and "disagree" that the residential neighborhood is safe for children (RR $=0.83$, 95\% CI: 0.70-0.95). School characteristics (area-level) included: presence of a walk/bike to school day program or a walking school bus program (RR $=0.89$, 95\% CI: 0.74-1.03). Neighborhood characteristics (area-level) included: a higher percentage of roads with sidewalks (quartile 3: $\mathrm{RR}=1.17,95 \% \mathrm{CI}$ : 0.96-1.34); a higher speed limit of the school's road $(50 \mathrm{~km} / \mathrm{h}: \mathrm{RR}=1.22$, 95\% CI: 0.92-1.43; $\geq 60$ km/h: RR = 1.26, 95\% CI: 0.96-1.47); increased total length of roads (quartile 4: $R R=1.23,95 \%$ CI: 1.00-1.42,); litter in neighborhoods perceived as a major problem $(\mathrm{RR}=1.47,95 \% \mathrm{CI}$ : $1.16-1.57)$; presence of vacant or shabby housing $\left(\mathrm{p}_{\text {trend }}=0.19\right)$; a lower average daily temperature (quartile $2: \mathrm{RR}=0.77,95 \% \mathrm{CI}$ : 0.54-1.00; quartile 3: $\mathrm{RR}=0.76,95 \% \mathrm{CI}$ : 0.46-1.08); higher amounts of rain (quartile 4: $\mathrm{RR}=1.25,95 \% \mathrm{CI}$ : 0.91-1.45); and more extreme hot days in a year (quartile $4: R R=1.33,95 \%$ CI: 1.05-1.53).

Table 6 displays the PAR estimates for the correlates of active transportation to school that were present in the final model (multivariate model 3). We did not calculate the PAR for three variables, including the lack of walk/bike to school days, the presence of litter in the neighborhood, and the speed limit of the school's street due to the confusing RRs. These variables were ignored, as it does not make sense to reduce active transportation programs in schools, or to increase litter in neighborhoods, or to increase the speed limit of the school's road in order to increase active transportation to school. PAR estimates ranged from $2.3 \%$ to $10.8 \%$ (10.8\% being the number of cars in the household) for the individual-level variables and from $6.9 \%$ to $16.6 \%$ (16.6\% being average temperature) for the area-level variables. The ratings under potential to intervene column in Table 6 were based upon our judgment on the feasibility of intervening upon each of the listed correlates.

\section{Discussion}

We identified the most important hypothesized correlates of active transportation to school in Canadian youth residing close to their school using indicators of: 1) the strength of associations identified via regression analyses; 2) population attributable risk; and 3) the potential for intervention. The most important finding of this national study was that the choice to engage in active transportation to school was governed by multiple factors at the individual- and area-levels, as opposed to one or more very specific factors.

There are major differences between our study design and methods from those used in previous studies in this field. Our study involved a geographically diverse sample from across the country, but at the same time was limited to urban youth who lived in close proximity to their school (ie, within 1 mile or $1.6 \mathrm{~km}$ ) and would therefore likely not be eligible for school bussing. We measured multiple active transportation correlates at multiple levels, and because of this, employed multilevel analytical approaches.

Despite differences in study design and methods, many of the individual and family correlates that were identified in our study have been identified in previous studies that examined determinants of active transportation, such as gender [6,9-11], family structure [14,15], and the number of cars in the household [17]. However, unlike previous American studies which found that Hispanic and Black students were more likely to engage in active transportation to school $[6,12,13]$, we did not find any associations for ethnicity. This may be related to the 
Table 4 Bivariate and multivariate (Model 2) relationships of area-level characteristics and active transportation to school ( $\mathbf{N}=3$ 997)

\begin{tabular}{llcr}
\hline Area-level characteristic & $\begin{array}{c}\text { \% Engaged in } \\
\text { active } \\
\text { transportation }\end{array}$ & $\begin{array}{c}\text { Bivariate model } \\
\text { RR (95\% Cl) }\end{array}$ & $\frac{\text { Multivariate model 2 }}{\mathrm{RR} \mathrm{(95 \%} \mathrm{Cl)}}$ \\
\hline School Characteristics &
\end{tabular}

\section{School Characteristics}

Bicycle storage available in a safe location

$\begin{array}{llcr}\text { No } & 68.3 & 1.00 & 1.00 \\ \text { Yes } & 61.1 & 0.89(0.74-1.01) & 0.94(0.77-1.09)\end{array}$

Has walk/bike to school days and/or walking school bus programs

$\begin{array}{llcr}\text { No } & 64.3 & 1.00 & 1.00 \\ \text { Yes } & 58.8 & 0.90(0.77-1.02) & 0.91(0.74-1.06) \\ \text { No } & & & 1.00 \\ \text { Yes } & 64.4 & 1.00 & 0.95(0.79-1.09)\end{array}$

Neighborhood Characteristics

Sidewalk leading to school

No $\quad 57.1$

$\begin{array}{ll}\text { Yes } & 62.8\end{array}$

$\%$ of roads with sidewalks

$$
\begin{aligned}
& 1(1.45-47.20) \\
& 2(47.21-64.30) \\
& 3(64.31-84.49) \\
& 4(84.50-100) \\
& \text { P trend }
\end{aligned}
$$

Speed limit of school's road $(\mathrm{km} / \mathrm{h})$

$\begin{array}{ll}\leq 40 & 59.5 \\ 50 & 62.3 \\ \geq 60 & 69.6 \\ P \text { trend } & \end{array}$

$\%$ of roads with speed limit $\leq 60 \mathrm{~km} / \mathrm{h}$

$\begin{array}{ll}1(<90) & 60.9 \\ 2(90-93.99) & 65.1 \\ 3(94-99.99) & 60.1 \\ 4(100) & 63.8\end{array}$

$P$ trend

Total length of roads $(\mathrm{km})$

$$
\begin{aligned}
& 1(10.7-29.2) \\
& 2(29.3-37.0) \\
& 3(37.1-41.7) \\
& 4(41.71-73.7) \\
& P \text { trend }
\end{aligned}
$$

Street connectivity

$$
\begin{aligned}
& 1 \text { (lowest connectivity) } \\
& 2 \\
& 3 \\
& 4 \text { (highest connectivity) }
\end{aligned}
$$

1.00

1.00

$1.11(0.79-1.37)$

1.00

1.00

$1.06(0.87-1.23)$

$1.12(0.93-1.27)$

$1.16(0.97-1.32)$

0.071

1.00

$1.15(0.92-1.34)$

$1.23(0.94-1.43)$

0.12

1.00

$1.10(0.89-1.27)$

$1.06(0.85-1.24)$

$1.03(0.83-1.21)$

0.94

1.00

$1.10(0.92-1.27)$

$1.16(0.97-1.33)$

1.32 (1.15 - 1.46)

0.0005

1.00

1.00

1.20 (1.02 - 1.36)

$1.07(0.81-1.30)$

$0.96(0.65-1.25)$

$0.91(0.56-1.25)$

$1.11(0.87-1.32)$

$1.14(0.88-1.35)$ $1.03(0.76-1.27)$

0.86

1.00

$1.27(0.90-1.50)$

$1.32(0.96-1.53)$

0.13

1.00

$1.06(0.82-1.27)$

$1.08(0.84-1.29)$

$1.05(0.81-1.25)$

0.78

1.00

$0.99(0.72-1.25)$

$1.10(0.79-1.37)$

$1.27(0.94-1.52)$

0.070

$1.16(0.97-1.32)$

1.24 (1.06 - 1.39) 
Table 4 Bivariate and multivariate (Model 2) relationships of area-level characteristics and active transportation to school ( $\mathbf{N}=3$ 997) (Continued)

\begin{tabular}{|c|c|c|c|}
\hline$P$ trend & & 0.020 & 0.45 \\
\hline \multicolumn{4}{|l|}{ itter in neighborhood } \\
\hline No problem & 62.1 & 1.00 & 1.00 \\
\hline Minor problem & 61.6 & $1.03(0.89-1.15)$ & $1.05(0.88-1.19)$ \\
\hline Moderate problem & 62.9 & $0.99(0.77-1.18)$ & $1.11(0.82-1.33)$ \\
\hline Major problem & 91.8 & $1.48(1.24-1.57)$ & $1.48(1.17-1.58)$ \\
\hline$P$ trend & & 0.13 & 0.055 \\
\hline \multicolumn{4}{|l|}{ /acant or shabby housing } \\
\hline No problem & 62.7 & 1.00 & 1.00 \\
\hline Minor problem & 59.7 & $0.98(0.81-1.13)$ & $0.91(0.71-1.10)$ \\
\hline Moderate problem & 72.4 & $1.07(0.81-1.28)$ & $0.76(0.44-1.09)$ \\
\hline Major problem & 60.7 & $1.07(0.59-1.40)$ & $0.73(0.23-1.29)$ \\
\hline$P$ trend & & 0.70 & 0.11 \\
\hline \multicolumn{4}{|c|}{ Veighborhood SES (median family income, \$CAD) } \\
\hline $1(32984-56$ 979) & 66.5 & 1.00 & 1.00 \\
\hline $2(56980-67400)$ & 66.1 & $1.01(0.85-1.15)$ & $0.97(0.75-1.16)$ \\
\hline $3(67400-80300)$ & 60.7 & $0.94(0.77-1.10)$ & $1.02(0.80-1.19)$ \\
\hline $4(80301-108010)$ & 58.9 & $0.88(0.72-1.04)$ & $0.95(0.69-1.16)$ \\
\hline$P$ trend & & 0.086 & 0.77 \\
\hline \multicolumn{4}{|l|}{ Average temperature $\left({ }^{\circ} \mathrm{C}\right)$} \\
\hline $1(-4.45-2.75)$ & 62.4 & 1.00 & 1.00 \\
\hline $2(2.76-4.40)$ & 58.9 & $1.00(0.82-1.16)$ & $0.71(0.34-1.13)$ \\
\hline $3(4.41-7.40)$ & 59.5 & $1.00(0.83-1.16)$ & $0.79(0.30-1.30)$ \\
\hline $4(7.41-10.60)$ & 68.3 & $1.04(0.87-1.19)$ & $0.88(0.27-1.42)$ \\
\hline $\mathrm{P}$ trend & & 0.64 & 0.95 \\
\hline \multicolumn{4}{|l|}{ Average annual rain (mm) } \\
\hline $1(326-615)$ & 61.7 & 1.00 & 1.00 \\
\hline $2(616-1335)$ & 62.1 & $1.02(0.84-1.18)$ & $0.93(0.59-1.23)$ \\
\hline $3(1336-1700)$ & 66.3 & $1.01(0.84-1.16)$ & $1.25(0.79-1.50)$ \\
\hline $4(1701-3360)$ & 60.6 & $1.02(0.85-1.18)$ & $1.27(0.82-1.50)$ \\
\hline$P$ trend & & 0.82 & 0.33 \\
\hline \multicolumn{4}{|l|}{ Average annual snow (cm) } \\
\hline $1(87-200)$ & 68.2 & 1.00 & 1.00 \\
\hline $2(201-240)$ & 70.0 & $1.04(0.89-1.16)$ & $1.10(0.87-1.26)$ \\
\hline $3(241-310)$ & 51.7 & $0.85(0.69-0.99)$ & $0.88(0.59-1.13)$ \\
\hline $4(311-690)$ & 61.8 & $0.94(0.79-1.07)$ & $0.84(0.46-1.17)$ \\
\hline$P$ trend & & 0.11 & 0.19 \\
\hline \multicolumn{4}{|c|}{ Average annual number of hot days } \\
\hline $1(0-0.63)$ & 56.4 & 1.00 & 1.00 \\
\hline $2(0.64-4.65)$ & 63.5 & $1.13(0.94-1.30)$ & $1.19(0.84-1.46)$ \\
\hline $3(4.66-10.50)$ & 67.8 & $1.12(0.92-1.28)$ & $1.07(0.70-1.39)$ \\
\hline $4(10.51-26.00)$ & 65.4 & $1.14(0.95-1.31)$ & $1.15(0.74-1.46)$ \\
\hline $\mathrm{P}$ trend & & 0.16 & 0.69 \\
\hline
\end{tabular}


Table 4 Bivariate and multivariate (Model 2) relationships of area-level characteristics and active transportation to school ( $N=3$ 997) (Continued)

\begin{tabular}{llrr}
\hline Average annual number of cold days & & & \\
$1(0-4.5)$ & 63.3 & 1.00 & 1.00 \\
$2(4.6-26.0)$ & 60.9 & $0.99(0.82-1.14)$ & $1.17(0.75-1.42)$ \\
$3(26.1-50)$ & 64.9 & $1.03(0.86-1.18)$ & $1.17(0.62-1.46)$ \\
$4(50.1-110.5)$ & 61.5 & $0.96(0.78-1.13)$ & $1.14(0.45-1.49)$ \\
P trend & & 0.87 & 0.69
\end{tabular}

Model 2 controls for the significant variables by backwards selection from the first model (gender, family structure, family SES, number of cars in household, and perceived residential neighborhood safety).

$R R(95 \% \mathrm{Cl})=$ relative risk (95\% confidence interval).

differing ethnic minority compositions in the United States and Canada. We also did not find an association between the number of siblings and active transportation, while several others have identified such an association $[8,14,15,40]$. Finally, most other studies have found that youth with a lower family SES were more likely to engage in active transportation to school $[8,14,15,21]$. Our results showed more of a U-shape pattern with SES, wherein students in the middle SES categories were the most likely to engage in active transportation to school.

School correlates of active transportation are not well understood as few studies have investigated these associations. Our main finding for schools was that, of the three potential school correlates examined, only one was associated with active transportation. Specifically, and to our surprise, the presence of active transportation programs (walk/bike to school days and walking school bus programs) was negatively associated with active transportation to school. This may be an artifact of the lack of temporality in our cross-sectional study design. That is, it is possible that schools with lower active transportation rates implemented walk/bike to school days and walking school bus programs in an attempt to address this public health issue.

Several neighborhood factors were also correlated with active transportation to school. Consistent with findings from a recent systematic review, we found no association with street connectivity (a measure of the directness of travel routes), but a positive association with the percentage of streets with sidewalks and the total length of streets [20]. Our finding that climate measures were associated with active transportation to school differs from other studies that were not as geographically diverse $[6,23]$. We also investigated several neighborhood variables that, to date, have been unstudied. Of these, our findings suggest that there is a relationship between aspects of the environment that are related to safety and aesthetics (e.g., presence of sidewalks, presence of shabby housing, presence of litter).

As discussed above, several individual and area-level variables were correlated with active transportation in our study. In order to supply information for the development of informed policy, we identified the most important correlates based upon the strength of the identified association, its population attributable risk, and the potential for intervention (see Table 6). Using these criteria, the most important correlates of active transportation to school were gender, the perception of residential neighborhood safety, the percentage of roads with sidewalks, and the total length of streets. In order to increase female engagement in active transportation to school, interventions could follow similar existing programs, such as the LEAP program implemented in South Carolina [41]. Additionally, other programs, such as ENACT suggest that resident-led neighborhood programs are effective at increasing active transportation to school by improving perception of neighborhood safety, with safety in numbers [42].

At the area-level, we propose that the type of intervention would vary depending on whether it is an existing school or a newly constructed school. For existing schools, improvements to the existing active transportation infrastructure (e.g., traffic calming strategies, cross-walks, bicycle paths, new sidewalks and traffic diversion efforts), such as done by the Safe Routes to School intervention in California, may improve rates of active transportation to school [19]. Newly constructed schools should be built in active transportation friendly environments.

The main limitations of our study include the following methodological issues. First, this study may have been affected by selection, as after excluding multiple schools and students, our final sample was reduced from 26078 to 3997 (many students were removed because they did not reside in an urban core, and because they did not live within $\sim 1$ mile of their school). Third, there may be measurement error with the distance from school inclusion, as the geographical center of the postal code area was considered as a proxy for the students' home location. Due to the fact that these analyses were limited to urban areas, the estimated locations should be relatively precise [28]. Fourth, we only have information on the trip from home to school; differences in mode of transportation may exist between journeys going to and 
Table 5 Final multivariate model of the relationships of characteristics of the individual and family, school, and neighborhood with active transportation to school ( $N=3$ 997)

\begin{tabular}{|c|c|}
\hline \multirow[t]{2}{*}{ Characteristic } & Multivariate model 3 \\
\hline & RR $(95 \% \mathrm{Cl})$ \\
\hline \multicolumn{2}{|c|}{ Individual and Family Characteristics (Individual-level) } \\
\hline \multicolumn{2}{|l|}{ Gender } \\
\hline Male & 1.00 \\
\hline Female & $0.86(0.80-0.91)$ \\
\hline \multicolumn{2}{|l|}{ Family structure, living with: } \\
\hline Both mother and father & 1.00 \\
\hline One parent and one step-parent & $1.10(1.00-1.19)$ \\
\hline Single parent & $1.07(0.99-1.14)$ \\
\hline Other & $1.10(0.94-1.24)$ \\
\hline \multicolumn{2}{|l|}{ Family SES } \\
\hline Very well off & 1.00 \\
\hline Well off & $1.08(1.00-1.16)$ \\
\hline Average & $1.16(1.08-1.24)$ \\
\hline Not very well off & $1.14(1.01-1.26)$ \\
\hline Not at all well off & $1.00(0.80-1.19)$ \\
\hline$P$ trend & 0.0041 \\
\hline \multicolumn{2}{|l|}{ Number of cars in household } \\
\hline 0 & 1.00 \\
\hline 1 & $0.94(0.82-1.04)$ \\
\hline $2+$ & $0.87(0.74-0.97)$ \\
\hline$P$ trend & 0.0003 \\
\hline \multicolumn{2}{|c|}{ Residential neighborhood is safe for children } \\
\hline Strongly agree & 1.00 \\
\hline Agree & $1.00(0.94-1.07)$ \\
\hline Neither agree nor disagree & $0.95(0.86-1.03)$ \\
\hline Disagree & $0.83(0.70-0.95)$ \\
\hline Strongly disagree & $0.95(0.76-1.11)$ \\
\hline$P$ trend & 0.019 \\
\hline
\end{tabular}

School Characteristics (Area-Level)

Has walk/bike to school days and/or walking school bus programs

$$
\begin{array}{lc}
\text { No } & 1.00 \\
\text { Yes } & 0.89(0.74-1.03)
\end{array}
$$

Neighborhood Characteristics (Area-Level)

$\%$ of roads with sidewalks

$$
\begin{aligned}
& 1(1.45-47.20) \\
& 2(47.21-64.30) \\
& 3(64.31-84.49) \\
& 4(84.50-100) \\
& \text { P trend }
\end{aligned}
$$

\begin{tabular}{|c|c|}
\hline \multicolumn{2}{|c|}{ Speed limit of school's road (km/h) } \\
\hline$\leq 40$ & 1.00 \\
\hline 50 & $1.22(0.92-1.43)$ \\
\hline$\geq 60$ & $1.26(0.96-1.47)$ \\
\hline$P$ trend & 0.13 \\
\hline \multicolumn{2}{|c|}{ Total length of roads (km) } \\
\hline $1(10.7-29.2)$ & 1.00 \\
\hline $2(29.3-37.0)$ & $1.00(0.76-1.22)$ \\
\hline $3(37.1-41.7)$ & $1.08(0.85-1.29)$ \\
\hline $4(41.71-73.7)$ & $1.23(1.00-1.42)$ \\
\hline$P$ trend & 0.031 \\
\hline \multicolumn{2}{|l|}{ Litter in neighborhood } \\
\hline No problem & 1.00 \\
\hline Minor problem & $1.05(0.89-1.18)$ \\
\hline Moderate problem & $1.09(0.83-1.29)$ \\
\hline Major problem & $1.47(1.16-1.57)$ \\
\hline$P$ trend & 0.061 \\
\hline \multicolumn{2}{|c|}{ Vacant or shabby housing } \\
\hline No problem & 1.00 \\
\hline Minor problem & $0.95(0.77-1.11)$ \\
\hline Moderate problem & $0.83(0.52-1.13)$ \\
\hline Major problem & $0.76(0.29-1.26)$ \\
\hline$P$ trend & 0.19 \\
\hline \multicolumn{2}{|c|}{ Average temperature $\left({ }^{\circ} \mathrm{C}\right)$} \\
\hline $1(-4.45-2.75)$ & 1.00 \\
\hline $2(2.76-4.40)$ & $0.77(0.54-1.00)$ \\
\hline $3(4.41-7.40)$ & $0.76(0.46-1.08)$ \\
\hline $4(7.41-10.60)$ & $0.87(0.53-1.19)$ \\
\hline$P$ trend & 0.71 \\
\hline \multicolumn{2}{|c|}{ Average annual rain (mm) } \\
\hline $1(326-615)$ & 1.00 \\
\hline $2(616-1335)$ & $0.94(0.68-1.18)$ \\
\hline $3(1336-1700)$ & $1.16(0.76-1.42)$ \\
\hline $4(1701-3360)$ & $1.25(0.91-1.45)$ \\
\hline$P$ trend & 0.20 \\
\hline \multicolumn{2}{|c|}{ Average number of hot days } \\
\hline $1(0-0.63)$ & 1.00 \\
\hline $2(0.64-4.65)$ & $1.24(0.95-1.46)$ \\
\hline $3(4.66-10.50)$ & $1.18(0.90-1.41)$ \\
\hline $4(10.51-26.00)$ & $1.33(1.05-1.53)$ \\
\hline$P$ trend & 0.057 \\
\hline
\end{tabular}

Table 5 Final multivariate model of the relationships of characteristics of the individual and family, school, and neighborhood with active transportation to school ( $\mathbf{N}=3$ 997) (Continued) 
Table 6 Population attributable risk and the potential for intervention of the correlates of active transportation to school

\begin{tabular}{|c|c|c|c|}
\hline Characteristic & PAR & $\begin{array}{l}\text { Potential to } \\
\text { intervene }\end{array}$ & How to intervene \\
\hline \multicolumn{4}{|l|}{ Individual Characteristics } \\
\hline Female gender & $7.1 \%$ & High & Safe walking programs directed towards females \\
\hline Not living with both parents & $2.8 \%$ & Low & \\
\hline Low family SES (< very well off) & $8.8 \%$ & Low & \\
\hline Cars in household ( 1 or more) & $10.8 \%$ & Low & \\
\hline Low perceived neighborhood safety & $2.3 \%$ & High & $\begin{array}{l}\text { Determine what makes a neighborhood feel safe and direct } \\
\text { intervention towards these factors }\end{array}$ \\
\hline \multicolumn{4}{|l|}{ Neighborhood Characteristics } \\
\hline$\%$ of roads with sidewalks (> quartile 1) & $9.5 \%$ & High & Construction of sidewalks on roads that have none \\
\hline Total length of roads (> quartile 1) & $6.9 \%$ & High & $\begin{array}{l}\text { Building new schools in areas with more streets; or increasing multi-use } \\
\text { trails }\end{array}$ \\
\hline $\begin{array}{l}\text { No problem with vacant or shabby } \\
\text { housing }\end{array}$ & $10.4 \%$ & Low & Improve the aesthetics of neighborhoods where children live \\
\hline Low average temperature (quartile 1) & $16.6 \%$ & Low & \\
\hline High total rain (quartiles 3 and 4) & $9.8 \%$ & Low & \\
\hline High number of hot days (> quartile 1) & $16.1 \%$ & Low & \\
\hline
\end{tabular}

$R R=$ Relative Risk, $P A R=$ Population Attributable Risk.

leaving from school [5,9]. Fifth, outside of family structure and number of vehicles in the home, we were not able to examine potential parental correlates, and parents are clearly very involved in transportation decisions for their children. Sixth, due to the cross-sectional nature of the data, temporality between the variables cannot be assured. Finally, although there was sufficient power to study the individual and family variables and active transportation to school, power was more limited for the school and neighborhood variables.

\section{Conclusion}

Potential correlates of active transportation (at the individual- and area-levels) among urban youth living within close proximity to their school were examined using multi-level analytical methods. We found that the decision to engage in active transportation to school was affected by multiple factors at multiple levels. We identified gender, perception of residential neighborhood safety, the percentage of streets with sidewalks, and the total length of roads as the most important correlates of active transportation to school. Recommendations for interventions (e.g., safe-walking programs directed towards girls, and improvements to active transportation infrastructure) were made with the purpose of informing the development of future intervention and policy-based research aimed at increasing engagement in active transportation to school in youth.

\section{Abbreviations}

Cl: Confidence interval; GIS: Geographic information systems; HBSC: Health Behaviour in School-Aged Children Survey; ICC: Intra-class correlation;
OR: Odds ratio; PAR: Population attributable risk; RR: Relative risk; SES: Socioeconomic status.

\section{Competing interests}

The authors declare that they have no competing interests.

\section{Authors' contributions}

All three authors designed the study. KG completed the statistical analyses with support and advice from WP and IJ. KG wrote the initial draft of the paper, which was extensively edited by WP and IJ. All authors read and approved the final manuscript.

\section{Acknowledgements}

We thank Laura Seliske and Marianne Nichol for their informative background work. We also thank Andrei Rosu for the coordination of GIS data collection. This study was funded by an operating grant from the Canadian Institutes of Health Research (MOP 97962), and a second operating grant co-funded by the Canadian Institutes of Health Research and the Heart and Stroke Foundation of Canada (PCR 101415). In addition, Kathleen Gropp was supported by the Empire Life Fellowship (child health) of Kingston, Ontario and lan Janssen was supported by a Canada Research Chair award. The Health Behaviour in School-aged Children Survey (HBSC), a World Health Organization / European Region collaborative study, was funded in Canada by the Public Health Agency of Canada and Health Canada (Contract: 4500267124). The principal investigator of the 2010 Canadian HBSC was William Pickett, while John Freeman was the co-principal investigator and Matthew King was the national coordinator. The HBSC is coordinated internationally by Candace Currie (University of St. Andrews).

\section{Author details}

'Department of Community Health and Epidemiology, Queen's University, Kingston, ON, Canada. 'Department of Emergency Medicine, Queen's University, Kingston, ON, Canada. ${ }^{3}$ School of Kinesiology and Health Studies, Queen's University, Kingston, ON K7L 3N6, Canada. 


\section{References}

1. Sallis JF, Frank LD, Saelens BE, Kraft MK: Active transportation and physical activity: opportunities for collaboration on transportation and public health research. Transport Res A-Pol 2004, 38:249-268.

2. Dollman J, Lewis NR: Active transport to school as part of a broader habit of walking and cycling among South Australian youth. Pediatr Exerc Sci 2007, 19:436-443.

3. Lubans DR, Boreham CA, Kelly P, Foster CE: The relationship between active travel to school and health-related fitness in children and adolescents: a systematic review. Int J Behav Nutr Phys Act 2011, 8:5.

4. Buliung RN, Mitra R, Faulkner G: Active school transportation in the Greater Toronto Area, Canada: an exploration of trends in space and time (1986-2006). Prev Med 2009, 48:507-512.

5. Ham SA, Martin S, Kohl HW: Changes in the percentage of students who walk or bike to school-United States, 1969 and 2001. J Phy Act Health 2008, 5:205-215.

6. Babey SH, Hasert TA, Huang W, Brown ER: Sociodemographic, family, and environmental factors associated with active commuting to school among US adolescents. J Public Health Policy 2009, 30:203-220.

7. McDonald NC: Active transportation to school. Am J Prev Med 2007, 32:509-516.

8. MCMillan TE: The relative influence of urban form on a child's travel mode to school. Trans Res A 2007, 41:69-79.

9. Larsen K, Gilliland J, Hess P, Tucker P, Irwin J, He M: The influence of the physical environment and sociodemographic characteristics on children's mode of travel to and from school. Am J Public Health 2009, 99:520-526.

10. Robertson-Wilson JE, Leatherdale ST, Wong SL: Social-ecological correlates of active commuting to school among high school students. J Adolesc Health 2008, 42:486-495.

11. Bungum T, Lounsbery M, Moonie S, Gast J: Prevalence and correlates of walking and biking to school among adolescents. J Commun Health 2009, 34:129-134.

12. Braza M, Shoemaker W, Seeley A: Neighborhood design and rates of walking and biking to elementary school in 34 California communities. Am J Health Promot 2004, 19:128-136.

13. Evenson KR, Huston SL, McMillen BJ, Bors P, Ward DS: Statewide prevalence and correlates of walking and bicycling to school. Arch Pediatr Adolesc Med 2003, 157:887-892.

14. Pabayo R, Gauvin L, Barnett TA: Longitudinal changes in active transportation to school in Canadian youth aged 6 through 16 years. Pediatrics 2011, 128:e404-e413.

15. Pabayo RA, Gauvin L, Barnett TA, Morency P, Nikiema B, Seguin L: Understanding the determinants of active transportation to school among children: evidence of environmental injustice from the Quebec Longitudinal Study of Child Development. Health Place 2012, 18:163-171.

16. Merom D, Tudor-Locke C, Bauman A, Rissel C: Active commuting to school among NSW primary school children: implications for public health. Health Place 2006, 12:678-687.

17. Ewing R, Schroeer W, Greene W: School location and student travel: analysis of factors affecting mode choice. Transport Res Rec 2004, 1895:55-63.

18. Martin SL, Lee SM, Lowry R: National prevalence and correlates of walking and bicycling to school. Am J Prev Med 2007, 33:98-105.

19. Boarnet MG, Anderson CL, Day K, McMillan T, Alfonzo M: Evaluation of the California Safe Routes to School legislation: urban form changes and children's active transportation to school. Am J Prev Med 2005, 28:134-140.

20. Wong BY, Faulkner G, Buliung R: GIS measured environmental correlates of active school transport: a systematic review of 14 studies. Int J Behav Nutr Phys Act 2011, 8:39.

21. McDonald NC: Critical factors for active transportation to school among low-income and minority students. Evidence from the 2001 National Household Travel Survey. Am J Prev Med 2008, 34:341-344

22. McDonald NC, Deakin E, Aalborg AE: Influence of the social environment on children's school travel. Prev Med 2010, 50(Suppl 1):S65-S68.

23. Sirard JR, Ainsworth BE, Mclver KL, Pate RR: Prevalence of active commuting at urban and suburban elementary schools in Columbia, SC. Am J Prev Med 2009, 95:236-237.
24. Kerr J, Rosenberg D, Sallis JF, Saelens BE, Frank LD, Conway TL: Active commuting to school: Associations with environment and parental concerns. Med Sci Sports Exerc 2006, 38:787-794.

25. Booth ML, Okely AD, Denney-Wilson E, Hardy LL, Dobbins T, Wen L, Rissel C: Characteristics of travel to and from school among adolescents in NSW, Australia. J Paediatr Child Health 2007, 45:755-761.

26. Timperio A, Ball K, Salmon J, Roberts R, Giles-Corti B, Simmons D, Baur LA, Crawford D: Personal, family, social, and environmental correlates of active commuting to school. Am J Prev Med 2006, 30:45-51.

27. Currie C, Nic Gabhainn S, Godeau E: The Health Behaviour in School-aged Children: WHO Collaborative Cross-National (HBSC) study: origins, concept, history and development 1982-2008. Int J Public Health 2009, 54 (Suppl 2):131-139.

28. Bow CJ, Waters NM, Faris PD, Seidel JE, Galbraith PD, Knudtson ML, Ghali WA: Accuracy of city postal code coordinates as a proxy for location of residence. Int J Health Geogr 2004, 3:5.

29. Roberts C, Alexander D, Currie D, Haug E, Komkov A, Tynajala J: Physical activity. In Health Behaviour in School-aged Children (HBSC): Research protocol for the 2005/06 survey. Edinburgh: Child and Adolescent Health Research Unit; 2006.

30. Clarke P, Ailshire J, Melendez R, Bader M, Morenoff J: Using Google Earth to conduct a neighborhood audit: reliability of a virtual audit instrument. Health Place 2010, 16:1224-1229.

31. Janssen I, Rosu A: Measuring sidewalk distances using Google Earth. BMC Med Res Methodol 2012, 12:39.

32. Dill J: Measuring network connectivity for bicycling and walking. Washington, D.C: Transport Research Board 2004 Annual Meeting (CD-ROM); 2004.

33. Tresidder M: Using GIS to Measure Connectivity: An Exploration of Issues. School of Urban Studies and Planning: Portland State University; 2005.

34. Mecredy G, Pickett W, Janssen I: Street connectivity is negatively associated with physical activity in Canadian youth. Int J Environ Res Public Health 2011, 8:3333-3350.

35. Snijders $T A B$, Bosker RJ: Multilevel analysis: an introduction to basic and advanced multilevel modeling. London: SAGE Publications Ltd.; 1999.

36. Cerin E, Saelens BE, Sallis JF, Frank LD: Neighborhood environment Walkability scale: validity and development of a short form. Med SCi Sports Exerc 2006, 38:1682-1691.

37. de Vries SI, Hopman-Rock M, Bakker I, Hirasing RA, van Mechelen W: Built environmental correlates of walking and cycling in Dutch urban children: results from the SPACE study. Int I Environ Res Public Health 2010, 7:2309-2324.

38. Zhang J, Yu KF: What's the relative risk? A method of correcting the odds ratio in cohort studies of common outcomes. JAMA 1998, 280:1690-1691.

39. Rothman KJ, Greenland S: Modern epidemiology. New York, NY: Lippincott, Williams and Wilkins; 1998.

40. McDonald NC: Children's mode choice for the school trip: the role of distance and school location in walking to school. Transportation 2008, 35:22-35.

41. Ward DS, Saunders R, Felton GM, Williams E, Epping JN, Pate RR: Implementation of a school environment intervention to increase physical activity in high school girls. Health Educ Res 2006, 21:896-910

42. ENACT strategy: safe communities. [http://eatbettermovemore.org/sa/enact/ neighborhood/safety.php]

\section{doi:10.1186/1479-5868-9-124}

Cite this article as: Gropp et al:: Multi-level examination of correlates of active transportation to school among youth living within 1 mile of their school. International Journal of Behavioral Nutrition and Physical Activity 2012 9:124 